\title{
Comparative Study on Path Interval and Two Tool Condition Parameters in Ball and Filleted End Milling
}

\author{
Tsutomu Sekine ${ }^{1}$ \\ 1 Department of Systems Design Engineering, Faculty of Science and Technology, Seikei University, Tokyo, Japan \\ -mail: ts_s@outlook.com
}

\begin{abstract}
This study describes the comparisons of path interval determinations and two tool condition parameters in ball and filleted end milling. The selection of tool and its machining conditions is an ever-present challenge inherent in milling process. After the path interval determinations were explained briefly, the characteristics of each procedure were revealed with experimental verifications. The results of computational procedures showed good agreement with the experimental ones. Then, predominant frictional distance and cutting speed were proposed for effective selection of machining conditions. The discussion was given based on the results obtained from the demonstrations. Moreover, the relationships to path interval were elucidated in connection with a predictable or constantranging variation tendency. In conclusion, several findings contributable for the process planning were organized from the experimental and numerical evidences.
\end{abstract}

Keywords: path interval, tool condition parameter, machining condition, ball end mill, filleted end mill.

\section{INTRODUCTION}

Milling process is one of the widespread manufacturing technologies [1]. Numerical control machines such as machining center have been developed to automate the manufacturing processes. Computer-aided technologies have consistently assisted and contributed to the developments, and it is undoubted that advanced manufacturing have been created owing to these use [2]. Computeraided design (CAD) offers digital, creative environment of attractive products to users. A digital model created using CAD is a basic design in the following product manufacturing such as Computer-aided manufacturing (CAM) [3]. In process planning with CAM, there are a variety of machining parameters to maintain a proper state in milling process. In addition, it should be careful that these parameters affects surface quality, machining accuracy, manufacturing efficiency, and so on [4-7]. Tool path generation is one of the condition-setting processes. CAM is commonly used in tool path generation especially for multiaxis machine tools [8-11].
Path interval determination is a part of tool path generation, and it is well known that path interval is a dominant factor to control the balance between manufacturing efficiency and machined surface feature. A large number of studies related to path interval determination have been carried out from theoretical and practical perspectives to advance milling process. Most of the studies focuses on ball end milling [12-14]. The path interval can be calculated through solving an intersection problem between a designed shape and a cutting edge of ball end mill $[15,16]$. To extract the intersection problem, an arbitrary section is instantaneously introduced according to machining state.

There are the other tool geometries. A tool with flat or filleted shape is typically used in practical milling because of its high material removability, whereas geometrically elaborate treatment is required in the path interval determination. To our knowledge, the two kinds of procedures have been available to obtain a path interval in flat end milling. The one employs two dimensional procedure similar to that in ball end milling, and it considers a cutter profile on an imaginary section 
introduced geometrically [17-19]. The other relies on three dimensional expression of milling process, and it is unavoidable in increasing computational cost and complexity [20,21].

There are the similar research directions in filleted end milling. A few studies with the path interval determination raise a two dimensional intersection problem considering a relationship between designed shape and cutting edge projected instantaneously onto an arbitrary section [22-24], whereas the related studies are mostly based on three dimensional expression designed mainly for a computational procedure to overcome mathematical complexities [25-27]. Among them, a procedure with remarkable characteristics was reported to determine a proper path interval in multi-axis filleted end milling [28].

On the other hand, path interval determination has been considered so far only for controlling a scallop height on machined surface. The viewpoint is really important, while the related research works have implied that an influence of the other factors could not overlook in multi-axis end milling [29-31]. To optimize a milling state or machine surface's quality, research findings have been reported from various perspectives such as machining parameters [32, 33], dynamic parameters [34], tool properties [35], and workpiece properties [36]. However, the relationships between each factor and path interval determination have been untouched so far in this field of research, so that it would be extremely difficult to compare this study with the related studies. In other words, there still remain inestimable unclear and unrecognized things concerning the relationships.

The purpose of this study is to investigate the relationships between machining factors and path interval determination in end milling. Especially, this study focuses on frictional distance and cutting speed in ball and filleted end milling. The comparisons will be made to provide the practical findings for effective tool selection. The discussion will also be given based on the results obtained from the demonstrations. In conclusion, several outcomes will be organized from the experimental and numerical evidences.

\section{PATH INTERVAL DETERMINATION}

This section theoretically describes path interval determinations in both ball and filleted end milling. Then, the experiments were performed to verify the theoretical expressions in path interval determinations. Hereafter, assuming, for simplicity, that milling process is performed on a plane. In addition, the tool diameters were selected from the commonly-used sizes of both end mills having two straight cutting edges. Although ball end milling was performed without tool inclination, filleted end milling was conducted with tool inclination. The unit of tool inclination angle is expressed as deg. to aid an intuitive understanding.

\section{The theoretical calculation in ball end milling}

A path interval is usually defined as a crossfeed distance between adjacent tool paths. Unlike the definition, this study sets $L / 2$ as a notation of path interval denoting a unilateral distance from a tool center point to a section assumed situationally to measure scallop height $h$. Figure 1 shows several valuables related to path interval determination in ball end milling. Given that ball end mill with tip radius $R$ moves along a trajectory of the tool center point to create a designed shape and $h$ is predetermined, $L / 2$ is given as follows:

$$
\frac{L}{2}=\sqrt{2 R h-h^{2}}
$$

This path interval determination refers to $[15$, 16]. The path interval can be obtained through solving an intersection problem on an instantaneous section. Tool inclination angle does not affect path interval determination since the tool tip geometry of ball end mill is a hemisphere projected onto the assumed section.

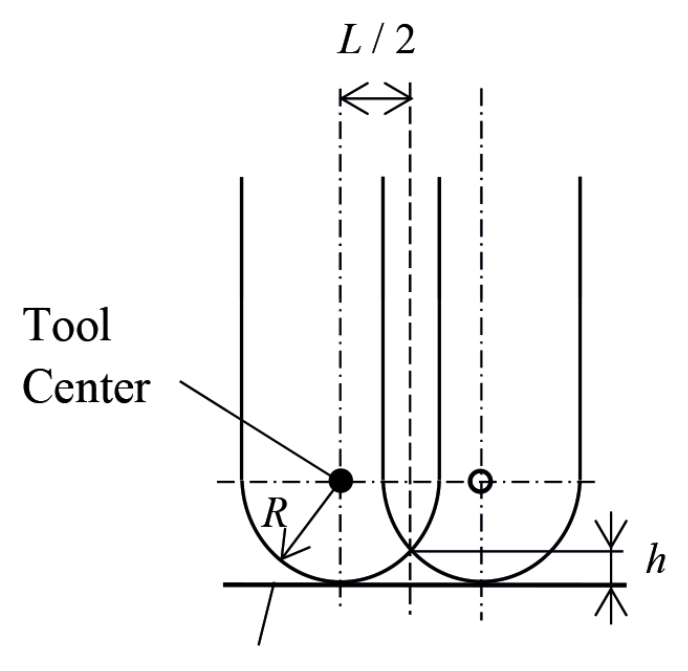

\section{A designed surface}

Fig. 1. A geometrical relationship between $L / 2$ and $h$ in ball end milling 


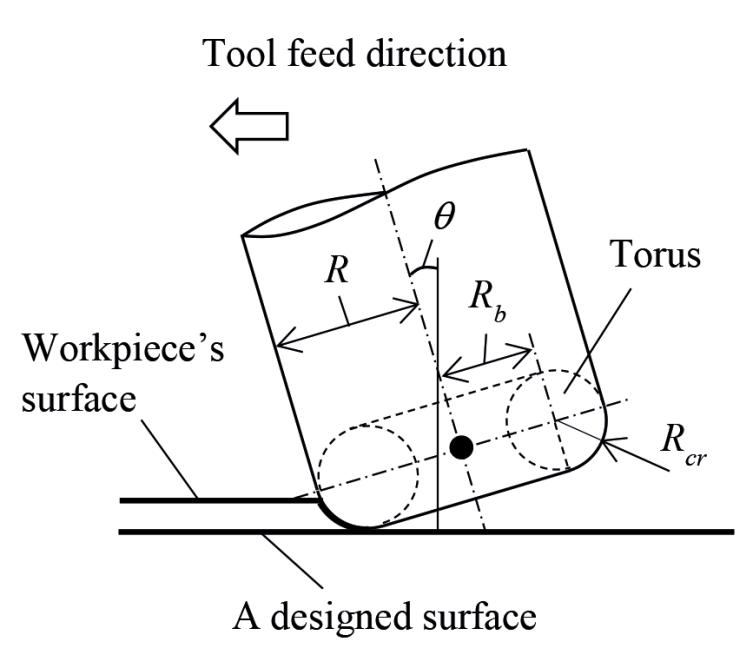

Fig. 2. Several radii and a tool inclination angle $\theta$ in filleted end milling

\section{The computational procedure in filleted end milling}

The remarkable algorithm was proposed for path interval determination in filleted end milling [28]. The procedure is employed in this study. In the algorithm, filleted end milling with a tool inclination is performed along a tool feed direction and on a plane to create a designed surface. Figure 2 shows several radii, i.e. $R, R_{b}$, and $R_{c r}$, of filleted end mill with a tool inclination along a tool feed direction. A tool inclination angle $\theta$ is also given in the figure. A torus is theoretically used to extract the characteristics of cutting edge geometry. With reference to [25], the step-by-step procedure was described in detail. The algorithm was improved, and the pseudo code was also demonstrated in our recent study [28]. After $L / 2$ is obtained as a result of iterative calculations, total path interval $L$ can be given as the summation of adjacent path intervals $L / 2$.

\section{Experiments}

Milling machine, PSF550-CNC, was used for experiments to verify the theoretical and computational approaches mentioned above. The appearance is given in Figure 3. The spindle has tilting mechanism, and the tilting range is available from -30 to $90 \mathrm{deg}$. In filleted end milling, tool inclination angle $q$ was properly adjusted in accordance with each experimental condition. Ball end mills (2BE) and filleted end mills (2RBE) were made by FUKUDA SEIKO Co., Ltd. They were individually attached to the milling machine's spindle in each experiment, and each radius of both tools was
$R=3.0,5.0,6.0$, and $7.0 \mathrm{~mm}$. Each corner radius $R_{c r}$ in filleted end milling was 1.0, 1.0, 2.0, and 3.0 $\mathrm{mm}$. A synthetic wood, SANMODUR MH-E, was used as a material to be machined. The material was clamped on a vice attached to the machine's table. Table 1 shows milling conditions in each ball end mill. In the table, condition B1a means tool number 1 with scallop height $0.05 \mathrm{~mm}$ in ball end milling. Accordingly, scallop height $0.10 \mathrm{~mm}$ is set in condition B1b. The others are also in the same manner. In contrast, Table 2 displays milling conditions in each filleted end mill. In the name of each condition, F means filleted end milling, and these conditions were given in accordance with the similar manner to the ones in ball end milling. These conditions were cautiously determined based on the results of preliminary investigations.

As shown in Figure 4, scanning-line tool paths from one direction were prepared according to each experimental conditions. With these motions, each path interval $L / 2$ was computationally determined a priori. In filleted end milling, scallop height $h$ was set as 0.05 and $0.10 \mathrm{~mm}$. The milling processes in each experimental condition were performed three times to investigate the repeatability of machined surface feature.

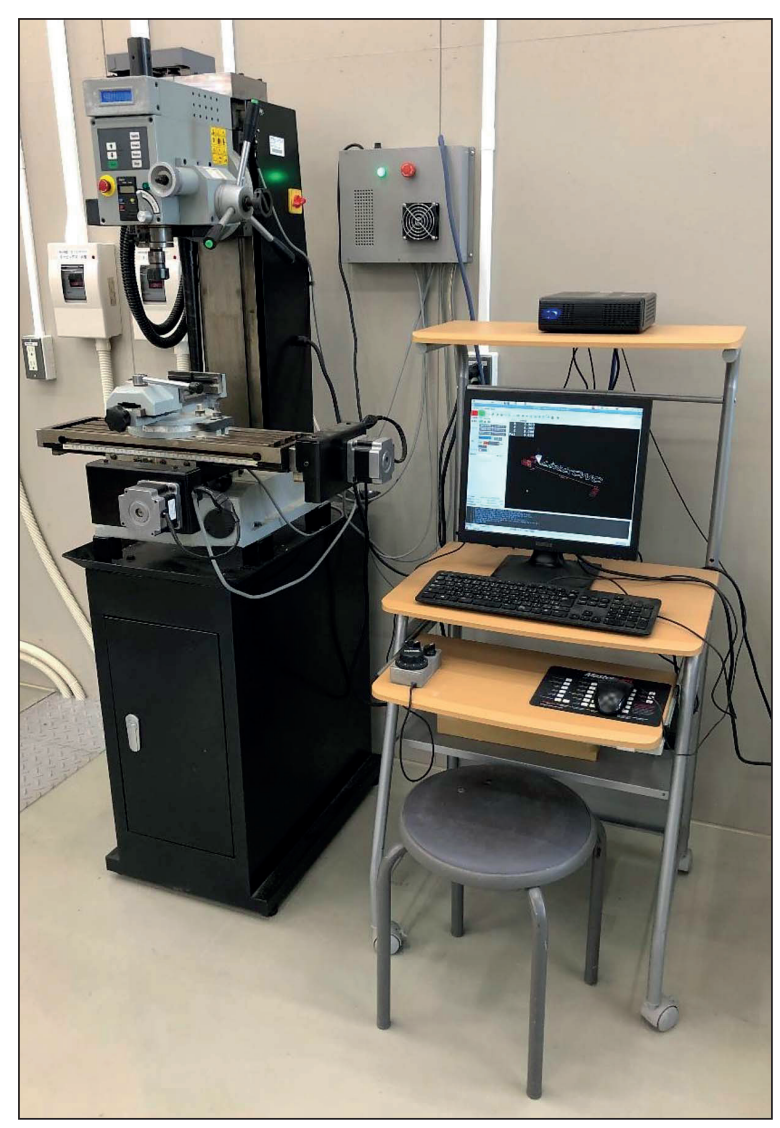

Fig. 3. CNC milling machine 
Table 1. Experimental conditions in ball end milling

\begin{tabular}{|l|c|c|c|c|c|c|c|c|}
\hline \multicolumn{1}{|c|}{ Parameters } & $\begin{array}{c}\text { Cond. } \\
\text { B1a }\end{array}$ & $\begin{array}{c}\text { Cond. } \\
\text { B1b }\end{array}$ & $\begin{array}{c}\text { Cond. } \\
\text { B2a }\end{array}$ & $\begin{array}{c}\text { Cond. } \\
\text { B2b }\end{array}$ & $\begin{array}{c}\text { Cond. } \\
\text { B3a }\end{array}$ & $\begin{array}{c}\text { Cond. } \\
\text { B3b }\end{array}$ & $\begin{array}{c}\text { Cond. } \\
\text { B4a }\end{array}$ & $\begin{array}{c}\text { Cond. } \\
\text { B4b }\end{array}$ \\
\hline Tool radius $R[\mathrm{~mm}]$ & 3.0 & 3.0 & 5.0 & 5.0 & 6.0 & 6.0 & 7.0 & 7.0 \\
\hline Tool rotational speed $S\left[\mathrm{~min}^{-1}\right]$ & 1400 & 1400 & 1400 & 1400 & 1200 & 1200 & 1200 & 1200 \\
\hline Feed rate $F[\mathrm{~mm} / \mathrm{min}]$ & 100 & 100 & 100 & 100 & 100 & 100 & 100 & 100 \\
\hline Scallop height $h[\mathrm{~mm}]$ & 0.050 & 0.100 & 0.050 & 0.100 & 0.050 & 0.100 & 0.050 & 0.100 \\
\hline Path interval $L / 2[\mathrm{~mm}]$ & 0.545 & 0.768 & 0.705 & 0.995 & 0.773 & 1.091 & 0.835 & 1.179 \\
\hline
\end{tabular}

Table 2. Experimental conditions in Filleted end milling

\begin{tabular}{|l|c|c|c|c|c|c|c|c|}
\hline \multicolumn{1}{|c|}{ Parameters } & $\begin{array}{c}\text { Cond. } \\
\text { F1a }\end{array}$ & $\begin{array}{c}\text { Cond. } \\
\text { F1b }\end{array}$ & $\begin{array}{c}\text { Cond. } \\
\text { F2a }\end{array}$ & $\begin{array}{c}\text { Cond. } \\
\text { F2b }\end{array}$ & $\begin{array}{c}\text { Cond. } \\
\text { F3a }\end{array}$ & $\begin{array}{c}\text { Cond. } \\
\text { F3b }\end{array}$ & $\begin{array}{c}\text { Cond. } \\
\text { F4a }\end{array}$ & $\begin{array}{c}\text { Cond. } \\
\text { F4b }\end{array}$ \\
\hline Tool radius $R[\mathrm{~mm}]$ & 3.0 & 3.0 & 5.0 & 5.0 & 6.0 & 6.0 & 7.0 & 7.0 \\
\hline Tool tip radius $R_{\text {er }}[\mathrm{mm}]$ & 1.0 & 1.0 & 1.0 & 1.0 & 2.0 & 2.0 & 3.0 & 3.0 \\
\hline Tool rotational speed $S\left[\mathrm{~min}^{-1}\right]$ & 1400 & 1400 & 1400 & 1400 & 1200 & 1200 & 1200 & 1200 \\
\hline Feed rate $F[\mathrm{~mm} / \mathrm{min}]$ & 100 & 100 & 100 & 100 & 100 & 100 & 100 & 100 \\
\hline Scallop height $h[\mathrm{~mm}]$ & 0.050 & 0.100 & 0.050 & 0.100 & 0.050 & 0.100 & 0.050 & 0.100 \\
\hline Path interval $L / 2[\mathrm{~mm}]$ & 1.442 & 1.879 & 2.090 & 2.843 & 2.115 & 2.884 & 2.140 & 2.924 \\
\hline
\end{tabular}

After the experiments, a specimen was cut out to measure a scallop height on a machined material. The cut-out part can be identified as a hatched area in Figure 5. Optical microscope (Mitutoyo TM-505) was exhibited in Figure 6 as an example of the observation and measurement after experiment. The scallop height was measured based on the observed image after the cut-out specimen was set on the stage of microscope. The measurements were made three times to achieve an average in each experimental condition. Then, these values were compared with the theoretical and computational ones.

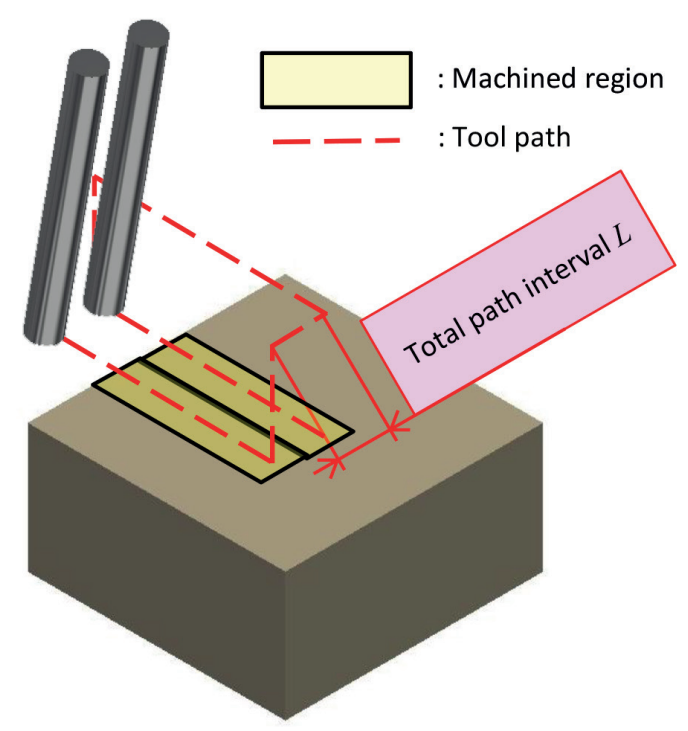

Fig. 4. A schematic illustration of tool path and machined region in experiment

\section{Results and verification}

Figures 7 and 8 show the experimental results in ball and filleted end milling. In both figures, each white bar graph with error bar indicates the average scallop height calculated using three experimental results in each condition. In contrast, each blue bar graph represents the computational value obtained using the above formula or procedure in each condition. The $\mathrm{x}$ axis on the graphs is labeled with tool radii used in experiments. The y axis on the graph is also labeled with scallop height $h[\mathrm{~mm}]$. From these results, computational values showed good agreement with experimental values. The differences were within plus or minus $0.05 \mathrm{~mm}$ at most. It means that the theoretical and computational

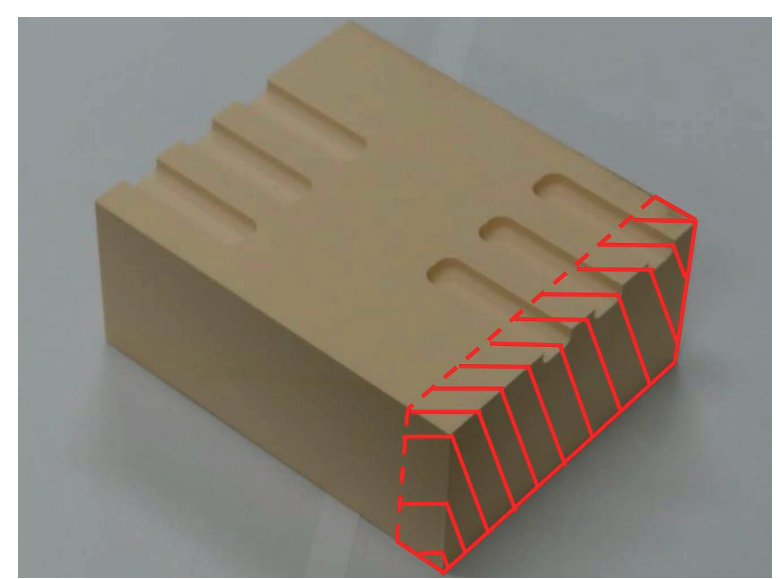

Fig. 5. A machined material before preparing a cut-out specimen 


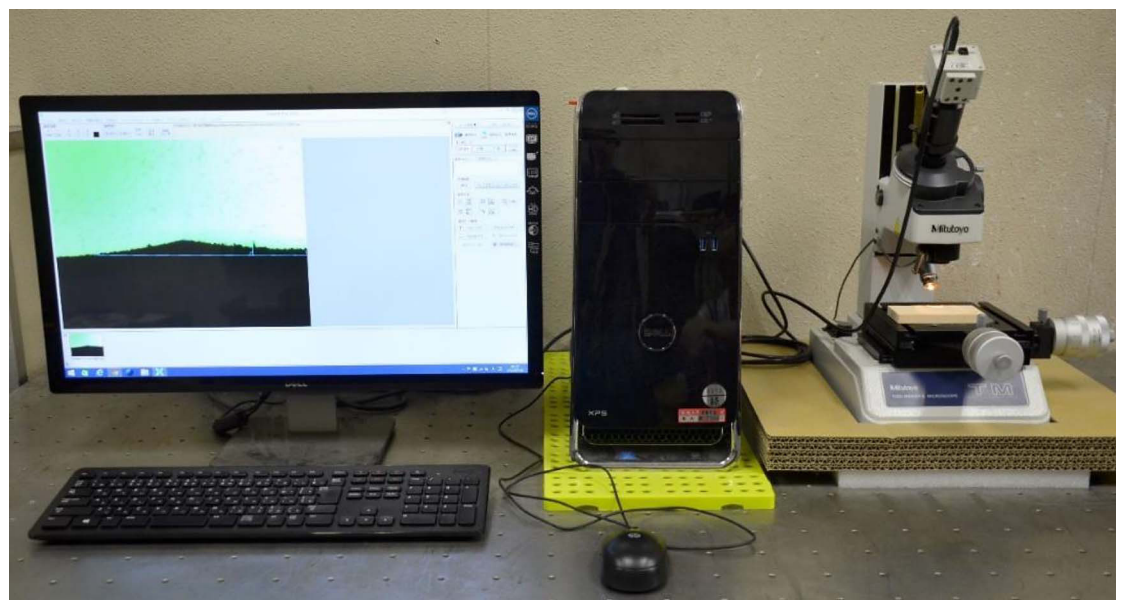

Fig. 6. An example of measuring a cut-out specimen

approaches proposed in this study can provide accurate estimations in each path interval determination. Moreover, the computational approach could offer predicted values with high accuracy even if the filleted end mill with different corner radius was used in each experiment. From Table 1 and 2, filleted end mill enables us to set more than twice the path interval, compared with the one in the corresponding radius of ball end mill. There were a little differences in this tendency. The increasing rate enlarged as the corner radius decreased in filleted end mill. When a scallop height was set to double value in the corresponding radius, the path intervals were given as about 1.4 times the values in ball end milling. The ratios of determined path intervals had similar tendency with practically considerable differences in filleted end milling. In all comparable cases, they were slightly smaller than the ones in ball end milling.

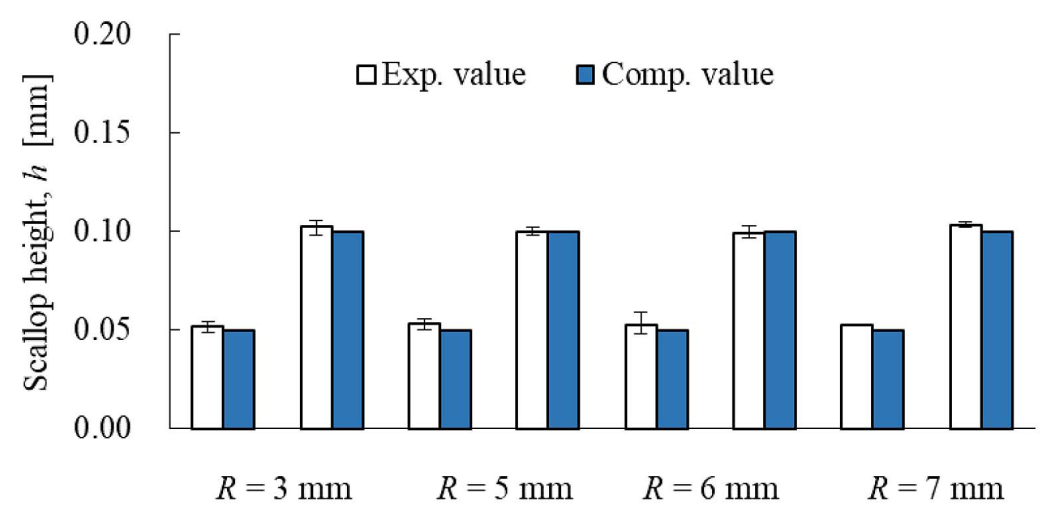

Fig. 7. Experimental verification of path interval determination in ball end milling for each tool radius

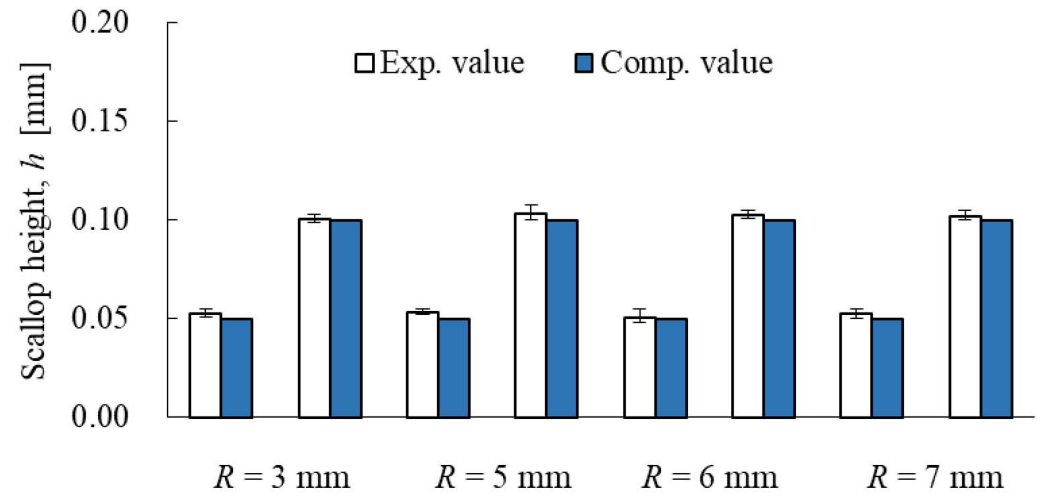

Fig. 8. Experimental verification of path interval determination in filleted end milling for each tool radius 


\section{TOOL CONDITION PARAMETERS}

This section describes tool condition parameters focusing especially on frictional distance and cutting speed in end milling. It is pointed out that the two parameters have direct influence on tool life [37]. Accordingly, the careful treatment is crucially necessary in determining cutting conditions. The theoretical procedures will be proposed based on the findings obtained previously in the related study [38]. Note that the demonstrations are targeted at one cutting edge during one rotation of a tool. The total value of frictional distance can be effortlessly obtained through calculating the summation. It is fact that a frictional distance of cutting point makes trochoid in end milling, whereas the influence is negligible when a feed length per cutting edge is small compared with tool radius. This study applied the approximate calculation to obtain a frictional distance of cutting point in end milling.

\section{Predominant frictional distance and cutting speed}

Ball end milling with the variables related to frictional distance and cutting speed is shown in Figure 9. Hereafter, we separately consider the first tool path and the subsequent ones in feed direction. For clarity, path number is added to all variables used below. Specifically, the number in parenthesis indicates path number, and the number 2 means the second tool path or above. From the drawing, $\alpha_{t z}$ and $R_{t z}$ are given as follows:

$$
\begin{aligned}
\alpha_{t z}(1) & =\frac{R-a p}{R} \\
R_{t z}(1) & =R \cos \alpha_{t z}
\end{aligned}
$$

Then, $\beta_{t z}$ was defined as a sliding contact angle around tool rotational axis. In the first tool path, the value of $\beta_{t z}$ is $180 \mathrm{deg}$. As a result, the predominant frictional distance $s l_{f d}$ can be obtained from the following formula:

$$
s l_{f d}(1)=R_{t z} \beta_{t z}
$$

In the second tool path or above, depth of cut $a p$ is substituted by scallop height $h$ in the half machining region. Hence, the following formulas can calculate the values of $\alpha_{t z}$ :

$$
\alpha_{t z}(2)=\frac{R-h}{R}
$$

Equations (3) and (4) can be similarly used to calculate $R_{t z}$ and $s l_{f d}$ in this case. Although a path interval $L / 2$ is considered in the calculation of $\beta_{t z}$, it is reasonable that the result is regarded as 180 deg. In addition, predominant cutting speed $v_{c s}$ is obtainable from the following formula:

$$
v_{c s}(1)=2 \pi R_{t z}(1) \frac{S}{1000}
$$

where: $S$ is a spindle speed in milling process. This equation can easily provide $v_{c s}(2)$ through substituting $R_{t z}(1)$ with $R_{t z}(2)$.

On the other hand, filleted end milling with the variables related to frictional distance and cutting speed is shown in Figure 10. What should be careful here is that $l_{a}$ and $l_{b}$ are necessary before calculations of the other parameters:

$$
\begin{aligned}
& l_{a}(1)=\left(R_{c r}-a p\right) \cos \theta \\
& l_{b}(1)=\left(R_{c r}-a p\right) \sin \theta
\end{aligned}
$$

Then, $\alpha_{t z}$ and $R_{t z}$ can be obtained using $l_{a}$ and $l_{b}$ :

$$
\begin{aligned}
& \alpha_{t z}(1)=\sin ^{-1}\left(\frac{l_{a}}{R_{c r}}\right) \\
& R_{t z}(1)=R_{c r} \cos \alpha_{t z}
\end{aligned}
$$

A sliding contact angle around tool rotational axis $\beta_{t z}$ can be calculated as follows:

$$
\beta_{t z}(1)=2 \cos ^{-1}\left(\frac{R_{b}+l_{b}}{R_{b}+R_{t z}}\right)
$$

Accordingly, the predominant frictional distance $s l_{f d}$ is derived from the following formula:

$$
s l_{f d}(1)=\left(R_{b}+R_{t z}\right) \beta_{t z}
$$

The similar manner used in ball end milling is applicable in the second tool path or above. In the several calculations of equations (7) and (8), depth of cut $a p$ is substituted by scallop height $h$ in the half machining region. After that, $\alpha_{t z}$ and $R_{t z}$ can be obtained using equations (9) and (10). In addition, a half angle of $\beta_{t z}$ is given with consideration of a path interval $L / 2$ :

$$
\beta_{t z}(2)=\sin ^{-1}\left(\frac{\frac{L}{2}}{R_{b}+R_{t z}}\right)
$$

With the calculation result, $s l_{f d}$ is provided as follows:

$$
s l_{f d}(2)=\left(R_{b}+R_{t z}\right)\left(\frac{\beta_{t z}(1)}{2}+\beta_{t z}(2)\right)
$$


Predominant cutting speed $v_{c s}$ is also obtainable from the following formula:

$$
v_{c S}(1)=2 \pi\left(R_{b}+R_{t z}(1)\right) \frac{S}{1000}
$$

This equation is available for calculating $v_{c s}(2)$ through substituting $R_{t z}(1)$ with $R_{t z}(2)$.

\section{Demonstrations and discussion}

As demonstrations, predominant frictional distances $s l_{f d}$ and cutting speeds $v_{c s}$ were calculated based on the experimental conditions. The tool inclination angle $\theta$ was set to $5.0 \mathrm{deg}$. in filleted end milling. Depth of cut $a p$ was also set to a half of $0.5 \mathrm{~mm}$ in all conditions. The results are shown in Tables 3 and 4. From these numerical results, $s l_{f d}$ increased with increasing tool radius. In the second tool path or above, the two parameters increased with increasing $h$ in the all tools. In the first tool path, the value of $s l_{f d}$ in ball end mill with the tool radius of $3.0,5.0$, or $6.0 \mathrm{~mm}$ was larger than the corresponding value in filleted end mill. The difference becomes clear more and more with decreasing the tool radius. This fact means that filleted end milling with small tool radius enables us to manage the value of $s l_{f d}$ in the low state. Here, we focuses on the ratios of $L / 2$ and $s l_{f d}(2)$. They can be rewritten using the conditions as follows: B1b / B1a, B2b / B2a, B3b / $\mathrm{B} 3 \mathrm{a}$, and B4b / B4a in ball end milling; moreover, F1b / F1a, F2b / F2a, F3b / F3a, and F4b / F4a

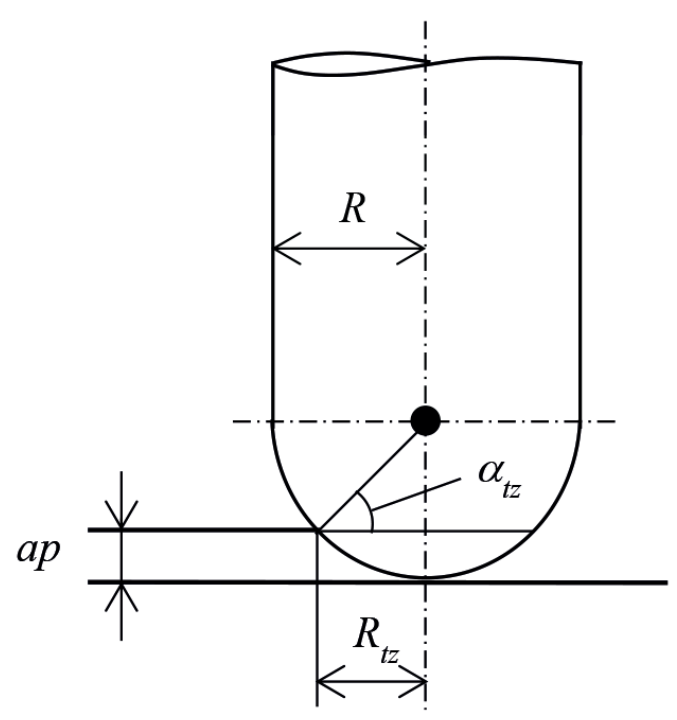

Fig. 9. The variables related to frictional distance and cutting speed in ball end milling in filleted end milling. The ratios of $L / 2$ in ball end milling are 1.409, 1.411, 1.411, and 1.412, respectively. In contrast, the ratios of $s l_{f d}(2)$ are $1.408,1.411,1.411$, and 1.412, respectively. From the numerical results, it is evident that the increasing rate of $s l_{f d}(2)$ with increasing $h$ is properly predictable from the increasing rate of $L / 2$ in ball end milling. In filleted end milling, the ratios of $L / 2$ are $1.303,1.360,1.363$, and 1.366 , respectively. In contrast, the ratios of $s l_{f d}(2)$ are 1.268 , $1.251,1.281$, and 1.300 , respectively. From these results, the increasing rate of $s l_{f d}(2)$ with increasing $h$ can be roughly estimated from the increasing rate of $L / 2$ in filleted end milling, whereas the accuracy of estimation decreases in filleted end mill with small corner radius.

The next attention was drawn to predominant cutting speed $v_{c s}$. In ball end milling, the $v_{c s}(2)$ is less than half of $v_{c s}(1)$ in each condition. Especially, ball end mill with small radius demonstrates relatively large decrease. On the other hand, the two cutting speeds have small, discernible differences in filleted end milling. Relatively large difference can be observed in filleted end mill with large corner radius. The findings mean that filleted end milling enables us to maintain a certain range of cutting speed $v_{c s}$ even if the machining state changes to make a designed surface.

\section{CONCLUSION}

This study describes the comparisons of path interval determinations in ball and filleted end milling. Predominant frictional distance and cutting

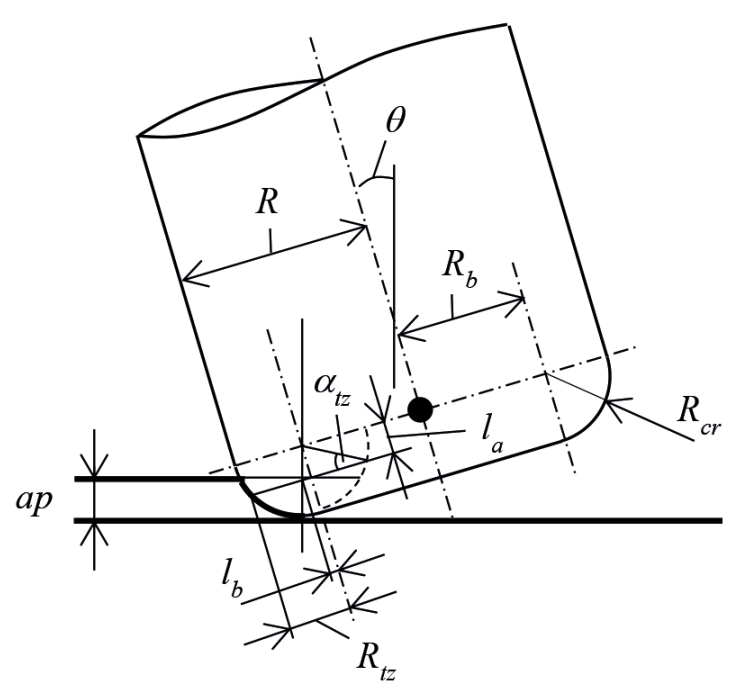

Fig. 10. The variables related to frictional distance and cutting speed in filleted end milling 
Table 3. Predominant frictional distances $s l_{f d}$ and cutting speeds $v_{c s}$ in ball end milling

\begin{tabular}{|c|c|c|c|c|c|c|c|c|}
\hline Parameters & $\begin{array}{c}\text { Cond. } \\
\text { B1a }\end{array}$ & $\begin{array}{c}\text { Cond. } \\
\text { B1b }\end{array}$ & $\begin{array}{c}\text { Cond. } \\
\text { B2a }\end{array}$ & $\begin{array}{c}\text { Cond. } \\
\text { B2b }\end{array}$ & $\begin{array}{c}\text { Cond. } \\
\text { B3a }\end{array}$ & $\begin{array}{c}\text { Cond. } \\
\text { B3b }\end{array}$ & $\begin{array}{c}\text { Cond. } \\
\text { B4a }\end{array}$ & $\begin{array}{c}\text { Cond. } \\
\text { B4b }\end{array}$ \\
\hline $\mathrm{R}[\mathrm{mm}]$ & 3.0 & 3.0 & 5.0 & 5.0 & 6.0 & 6.0 & 7.0 & 7.0 \\
\hline$s I_{f d}(1)[\mathrm{mm}]$ & 5.21 & 5.21 & 6.85 & 6.85 & 7.53 & 7.53 & 8.16 & 8.16 \\
\hline$s l_{f d}(2)[\mathrm{mm}]$ & 1.71 & 2.41 & 2.22 & 3.13 & 2.43 & 3.43 & 2.62 & 3.70 \\
\hline$v_{c s}(1)[\mathrm{m} / \mathrm{min}]$ & 14.59 & 14.59 & 19.17 & 19.17 & 18.08 & 18.08 & 19.59 & 19.59 \\
\hline$v_{c s}(2)[\mathrm{m} / \mathrm{min}]$ & 4.80 & 6.76 & 6.20 & 8.75 & 5.83 & 8.22 & 6.30 & 8.89 \\
\hline
\end{tabular}

Table 4. Predominant frictional distances $s l_{f d}$ and cutting speeds $v_{c s}$ in filleted end milling

\begin{tabular}{|c|c|c|c|c|c|c|c|c|}
\hline Parameters & $\begin{array}{c}\text { Cond. } \\
\text { F1a }\end{array}$ & $\begin{array}{c}\text { Cond. } \\
\text { F1b }\end{array}$ & $\begin{array}{c}\text { Cond. } \\
\text { F2a }\end{array}$ & $\begin{array}{c}\text { Cond. } \\
\text { F2b }\end{array}$ & $\begin{array}{c}\text { Cond. } \\
\text { F3a }\end{array}$ & $\begin{array}{c}\text { Cond. } \\
\text { F3b }\end{array}$ & $\begin{array}{c}\text { Cond. } \\
\text { F4a }\end{array}$ & $\begin{array}{c}\text { Cond. } \\
\text { F4b }\end{array}$ \\
\hline$R[\mathrm{~mm}]$ & 3.0 & 3.0 & 5.0 & 5.0 & 6.0 & 6.0 & 7.0 & 7.0 \\
\hline$R_{c r}[\mathrm{~mm}]$ & 1.0 & 1.0 & 1.0 & 1.0 & 2.0 & 2.0 & 3.0 & 3.0 \\
\hline$s l_{f d}(1)[\mathrm{mm}]$ & 4.46 & 4.46 & 5.75 & 5.75 & 7.29 & 7.29 & 8.31 & 8.31 \\
\hline$s l_{f d}(2)[\mathrm{mm}]$ & 2.13 & 2.70 & 2.90 & 3.62 & 3.33 & 4.26 & 3.59 & 4.67 \\
\hline$v_{e s}(1)[\mathrm{m} / \mathrm{min}]$ & 25.22 & 25.22 & 42.81 & 42.81 & 40.18 & 40.18 & 42.77 & 42.77 \\
\hline$v_{e s}(2)[\mathrm{m} / \mathrm{min}]$ & 20.43 & 21.49 & 38.03 & 39.08 & 33.75 & 35.03 & 34.71 & 36.26 \\
\hline
\end{tabular}

speed were also investigated as tool condition parameters. After path interval determinations were explained briefly, the characteristics of each procedure were revealed with experimental verifications. The results of computational procedures showed good agreement with the experimental ones. Then, predominant frictional distance $s l_{f d}$ and cutting speed $v_{c s}$ were proposed based on geometrical consideration. The equations were explained to calculate the two parameters in two machining states. From the comparisons in the first tool path, the value of $s l_{f d}$ in ball end mill with the tool radius of 3.0, 5.0 , or $6.0 \mathrm{~mm}$ was larger than the corresponding value in filleted end mill. The difference becomes clear more and more with decreasing the tool radius. The increasing rate of $s l_{f d}(2)$ with increasing $h$ is properly predictable from the increasing rate of $L / 2$ in ball end milling. In contrast, the increasing rate of $s l_{f d}(2)$ with increasing $h$ can be roughly estimated from the increasing rate of $L / 2$ in filleted end milling, whereas the accuracy of estimation decreases in filleted end mill with small corner radius. From the numerical results related to $v_{c s}$, filleted end milling enables us to maintain a certain range of cutting speed $v_{c s}$ even if the machining state changes to make a designed surface.

\section{Acknowledgments}

The authors would like to thank the financial support provided by OSG Fund and the research grant from Faculty of Science and Technology, Seikei University.

\section{Nomenclature}

\begin{tabular}{|l|l|}
\hline$L / 2$ & path interval [mm] \\
\hline$h$ & scallop height [mm] \\
\hline$R$ & tool radius of end mill [mm] \\
\hline$R_{c r}$ & corner radius of cutting edge in filleted end mill [mm] \\
\hline$R_{b}$ & $\begin{array}{l}\text { major radius of torus expressing cutting edge in } \\
\text { filleted end mill [mm] }\end{array}$ \\
\hline$\theta$ & tool inclination angle in filleted end milling [rad] \\
\hline$a p$ & depth of cut [mm] \\
\hline$S$ & spindle speed in milling process [min ${ }^{-1}$ ] \\
\hline$s l_{f d}(n)$ & predominant frictional distance [mm] \\
\hline$v_{c s}(n)$ & predominant cutting speed [m/min] \\
\hline$R_{t z}(n)$ & $\begin{array}{l}\text { radius calculated considering the height of ap on } \\
\text { tool rotational axis [mm] }\end{array}$ \\
\hline$\alpha_{t z}(n)$ & $\begin{array}{l}\text { angle calculated considering the height of ap on } \\
\text { tool rotational axis [rad] }\end{array}$ \\
\hline$\beta_{t z}(n)$ & sliding contact angle around tool rotational axis [rad] \\
\hline$I_{a}(n)$ & length requisite for the calculation of $\alpha_{t z}(\mathrm{n})$ \\
\hline$I_{b}(n)$ & length requisite for the calculation of $\beta_{\mathrm{tz}}(\mathrm{n})$ \\
\hline$n$ & the number of scanning line in tool path \\
\hline
\end{tabular}

\section{REFERENCES}

1. Mali R.A., Gupta T.V.K., Ramkumar J. A comprehensive review of free-form surface milling-Advances over a decade. Journal of Manufacturing Processes. 2021; 62: 132-167.

2. Al-wswasi M., Ivanov A., Makatsoris H. A survey on smart automated computer-aided process planning (ACAPP) techniques. Int J Adv Manuf Technol. 2018; 97: 809-832. 
3. Mourtzis D., Doukas M., Bernidaki D., Simulation in Manufacturing: Review and Challenges, Procedia CIRP. 2014; 25: 213-229.

4. Liang F., Kang C., Fang F. A review on tool orientation planning in multi-axis machining. International Journal of Production Research. 2020; 1-31.

5. Honeycutt A., Schmitz T.L. Milling Bifurcations: A Review of Literature and Experiment. J. Manuf. Sci. Eng. 2018; 140: 120801.

6. Peng T., Xu X. Energy-efficient machining systems: a critical review, Int J Adv Manuf Technol. 2014; 72: 1389-1406.

7. Moradnazhad M., Unver H.O. Energy efficiency of machining operations: A review. Proceedings of the Institution of Mechanical Engineers Part B J. Eng. Manufacture. 2016; 231: 1871-1889.

8. Konobrytskyi D., Hossain M.M., Tucker T.M., Tarbutton J.A., Kurfess T.R. 5-Axis tool path planning based on highly parallel discrete volumetric geometry representation: Part I contact point generation. Computer-Aided Design and Applications. 2018; 15: 76-89.

9. Bo P., Bartoň M., Plakhotnik D., Pottmann H. Towards efficient 5-axis flank CNC machining of free-form surfaces via fitting envelopes of surfaces of revolution, Comput. Aided Des. 2016; 79: 1-11.

10. Harik R.F., Gong H., Bernard A. 5-axis flank milling: A state-of-the-art review, Comput. Aided Des. 2013; 45: 796-808.

11. Mladenovic G.M., Tanovic L.M., Ehmann K.F. Tool path generation for milling of free form surfaces with feedrate scheduling, FME Transactions. 2015; 43: 9-15.

12. Balabokhin A., Tarbutton J. Iso-scallop tool path building algorithm "based on tool performance metric" for generalized cutter and arbitrary milling zones in 3-axis CNC milling of free-form triangular meshed surfaces. Journal of Manufacturing Processes. 2017; 28: 565-572.

13. Tuanl L.H., Makhanov S.S. Accurate Scallop Evaluation Method Considering Kinematics of Fiveaxis Milling Machine for Ball-end Mill, Materials Science and Engineering. 2020; 840: 012006.

14. Xu J., Zhang H., Sun Y. Swept surface-based approach to simulating surface topography in ball-end CNC milling. Int J Adv Manuf Technol. 2018; 98: 107-118.

15. Sekine T., Obikawa T. Normal-Unit-Vector-Based Tool Path Generation Using a Modified Local Interpolation for Ball-End Milling. Journal of Advanced Mechanical Design, Systems, and Manufacturing. 2010; 4: 1246-1260.

16. Obikawa T., Sekine T. A Higher-Order Formula of Path Interval for Tool-Path Generation, International Journal of Automation Technology. 2011; 5663-668.
17. Vickers G.W., Quan K.W. Ball-mills versus endmills for curved surface machining, Trans. ASME, J. Eng. Ind. 1989; 111: 22-26

18. Sekine T., Obikawa T. Novel path interval determination in 5-axis flat end milling, Applied Mathematical Modelling. 2015; 39: 3459-3480.

19. Liang F., Kang C., Lu Z., Fang F. Iso-scallop tool path planning for triangular mesh surfaces in multiaxis machining. Robotics and Computer-Integrated Manufacturing. 2021; 72: 102206.

20. Plakhotnik D., Lauwers B. Computing of the actual shape of removed material for five-axis flat-end milling, Computer-Aided Design. 2012; 44: 1103-1114.

21. Zhang X., Zhang W., Zhang J., Pang B., Zhao W. Systematic study of the prediction methods for machined surface topography and form error during milling process with flat-end cutter, Proceedings of the Institution of Mechanical Engineers Part B J. Eng. Manufacture. 2019; 233: 226-242.

22. Kruth J.P., Klewais P. Optimization and Dynamic Adaptation of the Cutter Inclination during FiveAxis Milling of Sculptured Surfaces, CIRP Annals. 1994; 43: 443-448.

23. Sekine T., Obikawa T., Hoshino M. Establishing a Novel Model for 5-Axis Milling with Filleted End Mill, Journal of Advanced Mechanical Design, Systems, and Manufacturing. 2012; 6: 296-309.

24. Bedi S., Ismail F., Mahjoob M.J., Chen Y. Toroidal Versus Ball Nose and Flat Bottom End Mills. International Journal of Advanced Manufacturing Technology. 1997; 13: 326-332.

25. Sekine T. A Computational Algorithm for Path Interval Determination in Multi-Axis Filleted End Milling. Adv. Sci. Technol. Res. J. 2020; 14: 198-205.

26. Quinsat Y., Lavernhe S., Lartigue C. Characterization of 3D surface topography in 5-axis milling. Wear. 2011; 271: 590-595.

27. Hendriko H. A hybrid analytical and discrete based methodology to calculate path scallop of helical toroidal cutter in fiveaxis milling, FME Trans. 2018; 46: 552-559.

28. Sekine T., Kameya K. Remarkable characteristics of a novel path interval determination in filleted end milling. Journal Européen des Systèmes Automatisés. 2021; 54: 461-468.

29. Khorasani A.M., Yazdi M.R.S., Safizadeh M.S. Analysis of machining parameters effects on surface roughness: a review. Int. J. Comput. Mater. Sci. Surf. Eng. 2012; 5: 68-84.

30. Perez I., Madariaga A., Arrazola P.J., Cuesta M., Soriano D. An analytical approach to calculate stress concentration factors of machined surfaces. Int. J. Mech. Sci. 2021; 190: 106040.

31. Käsemodel R.B., de Souza A.F., Voigt R., Basso I., Rodrigues A.R. CAD/CAM interfaced algorithm 
reduces cutting force, roughness, and machining time in free-form milling. Int J Adv. Manuf. Technol. 2020; 107: 1883-1900.

32. Wojciechowski S., Maruda R.W., Nieslony P., Krolczyk G.M. Investigation on the edge forces in ball end milling of inclined surfaces. International Journal of Mechanical Sciences. 2016; 119: 360-369.

33. Zhang X., Zhang J., Zheng X., Pang B., Zhao W. Tool orientation optimization of 5-axis ball-end milling based on an accurate cutter/workpiece engagement model. CIRP Journal of Manufacturing Science and Technology. 2017; 19: 106-116.

34. Altintaş Y., Budak E. Analytical Prediction of Stability Lobes in Milling, CIRP Annals. 1995; 44: 357-362.
35. Habibi M., Kilic Z.M., Altintas Y. Minimizing Flute Engagement to Adjust Tool Orientation for Reducing Surface Errors in Five-Axis Ball End Milling Operations, ASME. J. Manuf. Sci. Eng. 2021; 143: 021009.

36. Masmiati N., Sarhan A.A.D. Optimizing cutting parameters in inclined end milling for minimum surface residual stress - Taguchi approach. Measurement. 2015; 60: 267-275.

37. Zhang G., Guo C. Modeling Flank Wear Progression Based on Cutting Force and Energy Prediction in Turning Process, Procedia Manufacturing. 2016; 5: 536-545.

38. Sekine T. Study on Tool Condition Parameters Intended for Smart Tool Management in Filleted end Milling. Adv. Sci. Technol. Res. J. in press. 